F. Reprod. Fert. (1969) 19, 405-415

\title{
BLOOD PRESSURE AND RESPIRATORY PATTERNS DURING HUMAN COITUS
}

\author{
G. A. FOX* AND BEATRICE FOX $\uparrow$ \\ †Guy's Hospital and St. Olave's Hospital, London \\ (Received 25th June 1968, revised 30th October 1968)
}

\begin{abstract}
Summary. Changes in blood pressure and in the pattern of respiration have been investigated during human coitus. The blood pressure was recorded continuously and respiration was studied by means of spirometry. A peak of blood pressure and a sudden change in respiratory pattern were noted at the male and female sexual climax, and it is suggested that these are replicable parameters.
\end{abstract}

\section{INTRODUCTION}

There are few experimental investigations of the natural coital process in human subjects; the relatively small literature on this topic deals mainly with extracoital orgasm.

Boas \& Goldschmidt (1932) made simultaneous recordings of the heart rate of a man and woman in coitus. There was a peak in the heart rate of the woman with each of her four orgasms, and of the man with ejaculation. Mendelsohn (1896) published pulse tracings recorded by Kolb during coitus. These tracings were used to illustrate the degree of exertion involved in coitus and its effect on the heart.

Bartlett (1956) repeated Boas \& Goldschmidt's experiment with three couples, with comparable results, and made observations on the respiratory system in addition to the heart rate. He reported also that there was frequently a striking degree of concordance between the heart rates of a man and woman in coitus, to the extent that the heart rate of one could on occasion respond to the partner's orgasm more intensely than to his own.

A further three experiments dealt with responses accompanying sexual orgasm attained through extra-coital methods (fantasy or self-stimulation). Klumbies \& Kleinsorge (1950) recorded blood pressure, heart rate and respiratory changes during orgasm, stimulated psychologically in the female and by masturbation in the male. They reported a rise in systolic blood pressure of $50 \mathrm{~mm}$ $\mathrm{Hg}$ in the female, from 110 to $160 \mathrm{~mm} \mathrm{Hg}$; and a rise of $130 \mathrm{~mm} \mathrm{Hg}$ in the male, from 120 to $250 \mathrm{~mm} \mathrm{Hg}$.

Mosovich \& Tallafero (1954) described electro-encephalogram changes during orgasm in consequence of self-stimulation in three women and three

\footnotetext{
* Postal address : 176 Charlton Road, London, S.E.7.
} 
men. They reported "At the acme of the orgasm ... there is a slowing of the electrical activity with increase in voltage until there are paroxysmal, three per second waves which are mixed with alternating muscular discharges". They drew attention to the similarity of EEG patterns occurring during orgasm and during epileptic convulsions. Hoenig \& Hamilton (1960) also discussed the relationship between epilepsy and orgasm, and described the case of an epileptic woman in whom orgasm triggered off seizures. They were able to induce orgasm and a seizure during an experimental hypnotic session.

Evidence from self-stimulatory experiments must be regarded with some reservation, since many of the events pertaining to the coital sequence are absent, and the effect of their absence cannot be predetermined.

A recent series of experiments has been carried out on human subjects by Masters \& Johnson (1966) to study orgasm elicited by masturbation, coitus and artificial coitus. The authors claimed that no distinction exists between the three forms of stimulation. We do not feel we can accept this claim at the present stage of knowledge. One amongst many obvious distinctions between artificial and natural coitus is the absence of detumescence in the 'electronic penis'.

Masters \& Johnson (1966) supplied data culled from hundreds of subjects. Such mass methodology may well be suited to certain types of static observation, such as reporting the size of the average penis, but has limitations when applied to the examination of a sequence such as coitus where observations are best carried out on a single individual and then repeated on further individuals. A reconstruction from averages of what different individuals experienced at different points during the sequence may be quite independent of the true sequence itself.

Masters \& Johnson (1961) made observations on four infertile couples and one fertile couple during coitus. In their four infertile cases none of the females experienced orgasm during the observed coitus, whilst in the one fertile case orgasm was experienced. This is not discussed in the text.

The majority of Masters \& Johnson's (1966) observations were based on experiments involving artificially induced orgasm. Amongst their findings were listed changes in vaginal size and colour, clitoral position, penile size, breast and nipple size, muscular contraction (including uterine muscle), skin and sweat reactivity and cardio-respiratory measurements of various kinds. The authors maintained that a rise of 30 to $80 \mathrm{~mm} \mathrm{Hg}$ systolic blood pressure has been observed in female subjects and 40 to $100 \mathrm{~mm} \mathrm{Hg}$ systolic pressure in male subjects.

Masters \& Johnson appeared to dismiss the possibility of inhibitions due to the laboratory environment persisting in their subjects, saying, "they rapidly gained confidence in their ability to respond successfully while subjected to a variety of recording techniques". Farber (1967) criticized this aspect of Masters \& Johnson's experiments, i.e. the underplaying of the role of artificial laboratory environment. Bartlett (1956) alluded to the difficulties of putting coitus under observation, even when witnesses were out of the room and out of direct contact. Our own experiments would support this view, despite the fact that there were no outside witnesses at all. 


\section{PROCEDURE AND METHODS}

Our studies were carried out on one married couple aged 37 (male) and 32 (female), with 10 years mutual coital experience in the habitual environment of their own bedroom. The absence of observers introduced a minimum of psychological artifacts into the situation of natural coitus, though such artifacts could not be absolutely eliminated.

Single-case methodology (Shapiro, 1966) and scientific introspection or selfobservation, which have been profitably applied to a number of problems in neurophysiology (Adrian, 1946; 1968, personal communication), have been employed in the present study.

Attention has been focused primarily on human female responses, but recordings of human male responses are given since they may constitute parameters of orgasm which can be compared in other species.

During coitus the female assumed the supine position in all experiments, and attempts were made to emulate the coital pattern which was most typical for this couple. Further details of this pattern are given below.

\section{Experiment 1}

Systolic blood pressure was measured by a Winston blood pressure follower, which uses a digital cuff. This instrument cannot measure diastolic blood pressure. The experiment was repeated several times to ensure that the results were typical for the kind of coitus described.

A further check on the reliability of the blood pressure recorder was made by readings on a portable brachial sphygmomanometer of the kind conventionally used by medical practitioners. Readings were taken at rest, at the commencement of coitus, at intromission and at the point of female orgasm, with no significant differences from the corresponding points when measured by the Winston blood pressure follower.

\section{Experiment 2}

Using a Benedict-Roth spirometer with $\mathrm{CO}_{2}$ absorption, four spirographs, two male and two female, were obtained during four separate coitions. Recordings were never made simultaneously for both male and female.

The spirometer was initially filled with an oxygen/air mixture, and this was rebreathed from the spirometer, employing a nose-clip and rubber mouthpiece.

Experimental artifacts. As the spirometer only recorded for $3 \mathrm{~min}$, the tracing was taken as near to orgasm as possible. This made it impossible to study the breathing pattern during the whole of a typical coital sequence with double female orgasm. With a long history of shared coital experience, however, both partners would have discerned irregularities from a typical pattern.

In the process of adjusting to the recording machines the usual coital pattern was sometimes disrupted. Even with adjustment, some degree of restriction was imposed by the recording apparatus. Although the resulting inhibition did not necessarily eliminate any of the orgasms, there was a subjective impression of slight delay to orgasm beyond the time of its normal occurrence. On occasion 
the final female orgasm could be completely eliminated because the slight delay after ejaculation could render the penis over-flaccid and useless as a stimulant to orgasm.

When an estimate was made of the latent period between ejaculation and second female orgasm, where no recording equipment apart from a simple stop-watch impeded activity, a time interval of $42 \mathrm{sec}$ was observed, i.e. longer than when the recording equipment was used. One of the reasons for this was that ejaculation lasted longer than usual and there was no relaxation of hold during the period of ejaculation. It is not possible to draw conclusions about the extent or even occurrence of a delay as a result of psychological inhibitions.

\section{RESULTS}

\section{Experiment 1}

Text-fig. 1 illustrates the variation in systolic blood pressure recorded for the female during a typical coitus. Blood pressure started at $100 \mathrm{~mm} \mathrm{Hg}$ and rose to $200 \mathrm{~mm} \mathrm{Hg}$ during the first orgasm. It then fell sharply to $142 \mathrm{~mm} \mathrm{Hg}$, with a rise of only $13 \mathrm{~mm} \mathrm{Hg}$ at the point of ejaculation. Approximately $30 \mathrm{sec}$ after ejaculation there was a final rise to $190 \mathrm{~mm} \mathrm{Hg}$ at the second orgasm, which was slightly lower than the figure during the first orgasm.

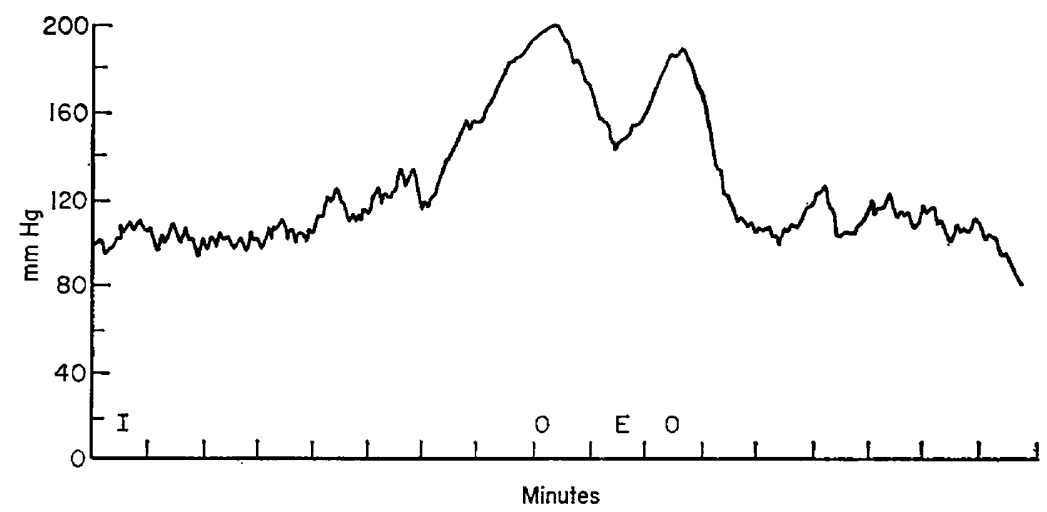

Text-Fig. 1. A recording of systolic blood pressure during coitus in one female subject. $I=$ intromission achieved; $\mathrm{O}=$ female orgasm; $\mathbf{E}=$ ejaculation.

For the male, blood pressure rose to a peak, from $110 \mathrm{~mm} \mathrm{Hg}$ to $175 \mathrm{~mm} \mathrm{Hg}$, at the point of ejaculation and then dropped sharply thereafter (Text-fig. 2). On another occasion, when the male did not await the first female orgasm, the systolic blood pressure rose only to $140 \mathrm{~mm} \mathrm{Hg}$.

The recordings in the above two figures are representative for the pattern of coitus occurring most frequently in this couple.

Blood characteristics. A further experiment to determine the effects of coitus on some characteristics of the female blood gave inconclusive results, except in one respect. Venous blood taken immediately before coitus has the normal burgundy hue, but immediately after coitus blood drawn from the vein takes on the colour of arterial blood (a bright scarlet). 


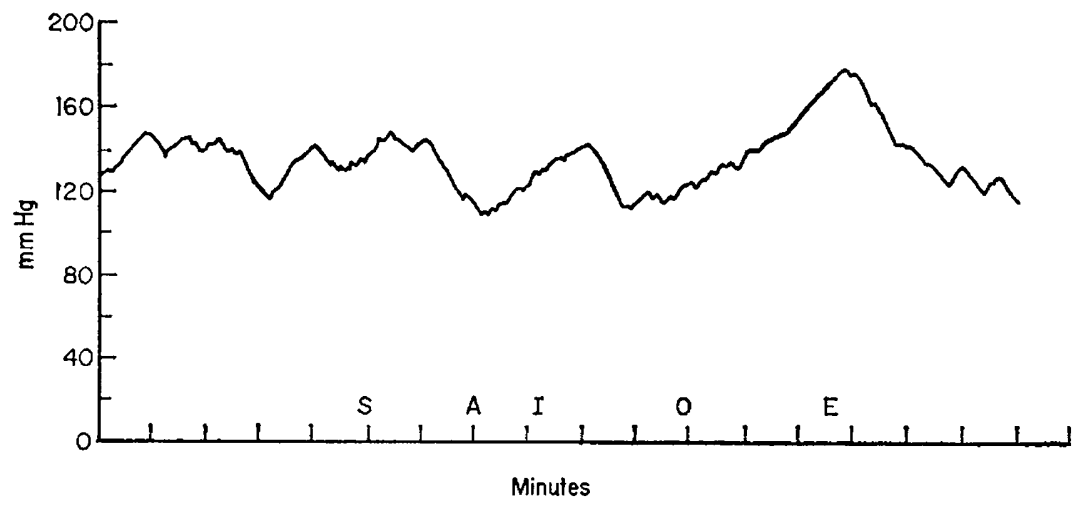

TexT-Fig. 2. A recording of systolic blood pressure during coitus in one male subject. $\mathrm{S}=$ start of timing; $\mathrm{A}=$ attempted intromission; $\mathrm{I}=$ intromission achieved; $\mathrm{O}=$ female orgasm; $E=$ ejaculation.
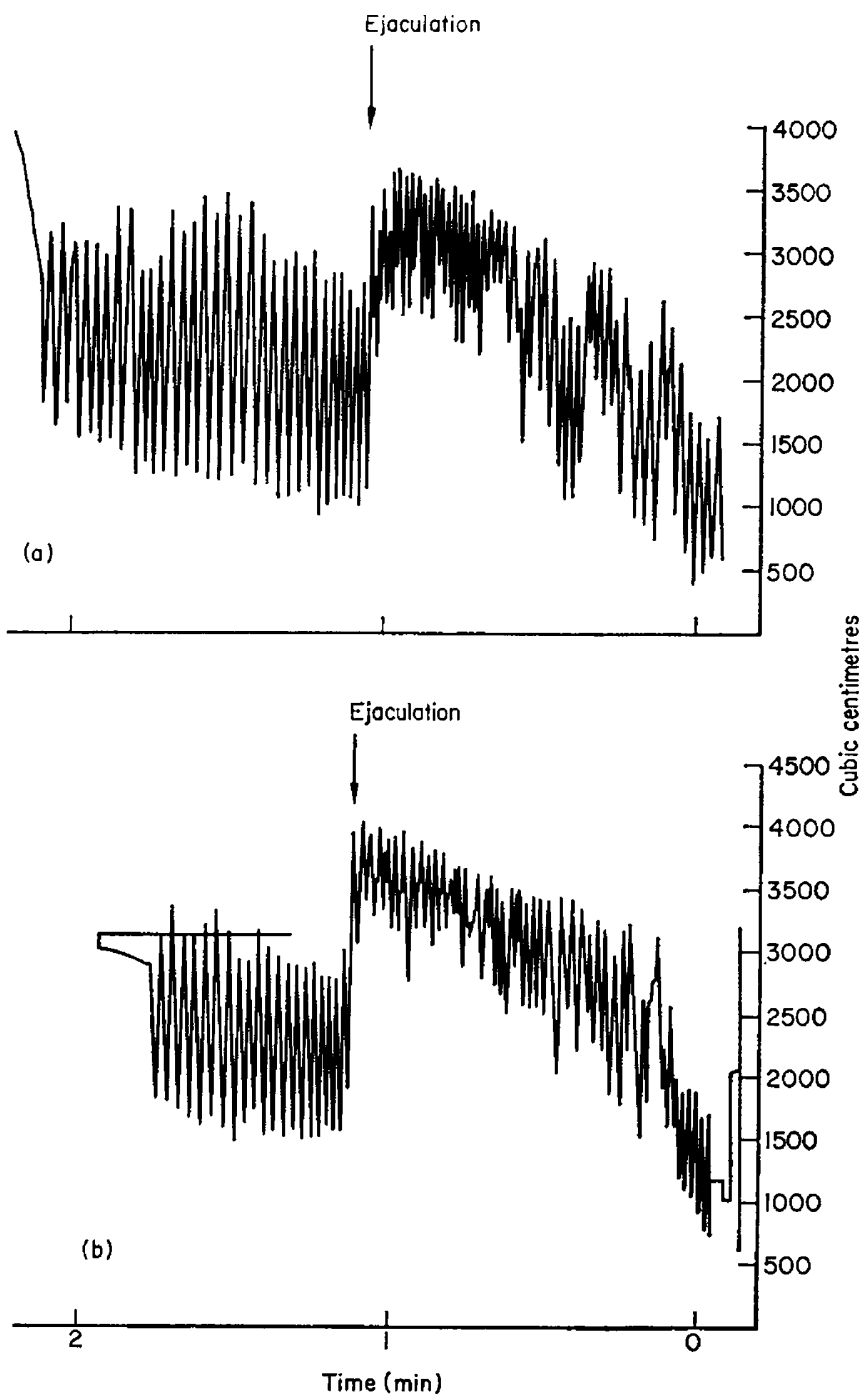

TeXT-FIG. 3. Spirographs for the male subject during the minute before and the minute after ejaculation in two experiments. 


\section{Experiment 2}

Spirometer tracings are shown in the two figures below. Text-figure 3 refers to the male subject. At the 1-min interval, which also represents the point of ejaculation, a sudden change in pattern was observed. This change is almost identical for both male experiments.

Immediately following ejaculation, a striking hyperventilation occurred.

The first female tracing (Text-fig. 4) differed from the male tracings in certain respects. Before female orgasm bouts of inspiratory apnoea were noticeable, whereas there were none in the male. A second female recording also

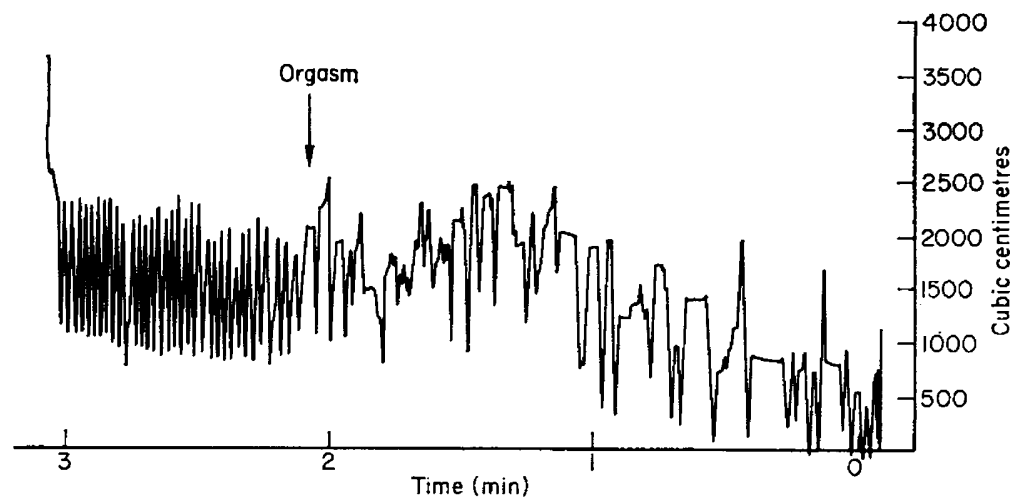

TEXT-FIG. 4. Spirograph for the female subject taken as near to orgasm as possible.

TABLE 1

RESPIRATORY RATE AND MINUTE VOLUME DURING COITUS

\begin{tabular}{l|cc|cc}
\hline & \multicolumn{2}{|c|}{ Respiratory rate/min } & \multicolumn{2}{c}{ Minute volume $(l /$ min $)$} \\
\cline { 2 - 3 } \cline { 5 - 6 } & $\begin{array}{l}\text { Before } \\
\text { climax }\end{array}$ & $\begin{array}{c}\text { After } \\
\text { climax }\end{array}$ & $\begin{array}{c}\text { Before } \\
\text { climax }\end{array}$ & $\begin{array}{c}\text { After } \\
\text { climax }\end{array}$ \\
\cline { 2 - 5 } & 41 & 30 & 39 & 51 \\
Text-fig. 3(a) (male) & 40 & 33 & 30 & 45 \\
Text-fig. 3(b) (male) & 40 & 37 & 13 & 44 \\
Text-fig. 4 (female) & 16 & & & \\
\hline
\end{tabular}

showed the apnoeic respiratory pattern before orgasm and the beginnings of a regular hyperventilation were apparent just before the tracing terminated.

The respiratory rate and minute volume can be determined from the tracings and are shown in Table 1.

It will be seen that, for the male, the pre-ejaculatory respiratory rate was of the order of $40 / \mathrm{min}$, while the post-ejaculatory respiratory rate dropped to $30 / \mathrm{min}$. The minute volume, however, showed a post-ejaculatory increase, i.e. the rate slowed down but the volume increased.

In the female, the respiratory rate before orgasm was much smaller than in the male, but corresponded closely to that of the male following orgasm. 


\section{AN INTROSPECTIVE DESGRIPTION OF FEMALE ORGASM}

The following section describes the pattern of coitus and orgasm occurring most frequently in this married couple over the past 10 years, and some indication is given of deviations from this pattern.

This female usually experiences two orgasms during coitus, one before the male ejaculates and a second about half a minute after ejaculation commences, and these are qualitatively different. The first sometimes tends to be fairly laboured, and the second occurs almost automatically. The second is very much more intense in feeling and occurs much more reliably than the first. The first orgasm is considerably more variable and inconstant than the second, occurring sometimes soon after the beginning of coitus, sometimes after a considerable time has elapsed and sometimes not at all. During periods of heightened excitement, the first orgasm might be intentionally eliminated, or alternatively could develop into multiple orgasms, i.e. about six or seven minor orgasms, if coitus lasts long enough. This depends on the responsiveness of the penis for when the penile reactions are swift, coitus ends quickly. The most noteworthy characteristic of the first (pre-ejaculatory) orgasms is their failure to satisfy. Whether one or six occur, the sensation of incompleteness and dissatisfaction remains. These orgasms seem to serve the purpose of ensuring a satisfactory state of excitement or responsiveness for the final (post-ejaculatory) orgasm, especially if the opportunity for foreplay is limited. With the final (post-ejaculatory) orgasm complete satisfaction is obtained, irrespective of the number of orgasms which preceded it.

Since the female orgasms occurring before the male's ejaculation are so qualitatively and temporally variable, there seems little purpose in attempting a subjective description, but the final post-ejaculatory orgasm warrants detailed description. With the final contractions of ejaculation, the male begins to relax his hold and become inert. At this point a compulsive abdominal and vaginal straining and heaving begins in the female. The penis seems to be pushed into the vaginal outlet, and the shaft is gripped just below the glans by the muscles at the vaginal outlet, until the glans is made to form a tightfitting plug in the vagina. At this stage the heaving reaches its maximum intensity and heralds the orgasmic contractions in the vagina and uterus at intervals of approximately $1 \mathrm{sec}$. The vaginal reaction to ejaculation is so automatic that it seems to have almost the quality of a reflex, and thus could, in times of stress, presumably fail. The vaginal contractions alternate with inward heaves, which carry with them a sensation of inward suction, though the intensely pleasurable orgasmic sensations are more allied to the contractions and the sense of relief these bring. The sensation of suction does not usually accompany clitoral or extra-coital orgasm.

A direct inverse relationship to the mechanism described above is the mechanism of ejaculation, whereby there is an outward pushing alternating with the contractions conveying orgasmic feelings.

In the female, the contractions of post-ejaculatory orgasms are usually accompanied by an emission of sound, which might be more characteristic of pain than of pleasure. There is, however, no question of pain. Sound is not 
a usual accompaniment of orgasms occurring before the male's ejaculation.

During the vaginal contractions, and possibly as a result of them, the penile 'plug' is ejected from the vagina and coitus is terminated. Active withdrawal by the male rarely takes place. Following an orgasm of this kind, the vagina feels 'closed' and very averse to further coital interference.

\section{Periods of heightened excitement}

These periods in the female appear to occur at intervals of certainly no less than a month and last from 3 to 4 days. At this stage no more can be said about the frequency or cause of their occurrence, except that they have been known to occur suddenly despite a stable and constant psychological environment. Moreover, psychological stimuli appearing outside such a period may have virtually no libidinal value at all. There is one possible exception to this: the sight or sound of a male ejaculating seems to act as a reliable trigger to such a period. These periods are characterized by an active approach to coitus on the part of the female in contrast to the usual attitude when the female, although she can be brought to respond at any time, is more passively co-operative.

\section{Blood pressure}

\section{DISCUSSION}

The results reported in the present study appertained to individuals in whom systolic blood pressure levels were essentially normal (female $=100 \mathrm{~mm} \mathrm{Hg}$, male $=120 \mathrm{~mm} \mathrm{Hg}$ ) and were well within the range of results quoted by Masters \& Johnson (1966). They are also consistent with the patterns of heartrate fluctuation given by Bartlett (1956) and Boas \& Goldschmidt (1932).

In all human experiments, a significant rise and a sharp fall in systolic blood pressure has been shown to accompany orgasm. The rise may be a function of the muscular effort involved or an autonomic measure of the orgasmic experience. In the present experiments, the second female orgasm showed a lower peak of blood pressure despite a higher subjective intensity of experience. The lowest rise for a female was that reported by Klumbies \& Kleinsorge (1950), where there could have been very little muscular effort involved, since the female reached orgasm by fantasy within about $25 \mathrm{sec}$ of the start of the experiment. The male took $15 \mathrm{~min}$ to achieve ejaculation by masturbation, which could imply a good deal of muscular effort and tension, and could account for the unusually high rise of $130 \mathrm{~mm} \mathrm{Hg}$. For the male, in the present experiments, there was usually little effort involved in ejaculating during coitus, and the blood pressure peak had been as low as $140 \mathrm{~mm} \mathrm{Hg}$. Scott (1930) described a mean rise in his subjects' systolic blood pressure of approximately $14 \mathrm{~mm} \mathrm{Hg}$ resulting from the showing of a film of a 'sexy' dancer. This presumably involved neither orgasm nor muscular activity.

\section{Blood colour}

The blood colour change has not been reported before, but this change might be related to the 'sex flush' described by Masters \& Johnson (1966). This effect might be produced by excessive dilatation of the veins during orgasm. 
Its function may be to ensure a speedy return of the blood pressure to its normal levels, or to facilitate the circulation of blood-borne hormones which may be required for the coital act, or even for subsequent fertilization.

\section{Oxytocin}

It has been suggested that oxytocin is released during human coitus (Harris \& Pickles, 1953; Campbell \& Peterson, 1953; Friberg, 1953), and its presence could well account for some of the circulatory manifestations at the point of orgasm in the present experiment, i.e. the fall in blood pressure, flushing and an increase in limb blood flow. In view of Campbell \& Peterson's description of the time lag for a neurohormonal reflex, it might also account for the relationship of ejaculation and female orgasm outlined in the present paper. The prostaglandins produce similar physiological changes (Bergström, 1967) and their release into the bloodstream during coitus and orgasm must be considered. The present authors are investigating the possibility of a release of oxytocin and/or prostaglandin during orgasm.

\section{Respiratory pattern}

The two male recordings (Text-fig. 3a, b) are interesting for the sudden change in respiratory pattern and it is this sudden change in respiratory pattern which may constitute a criterion for orgasm during natural coition.

This subject has been previously investigated by Klumbies \& Kleinsorge (1950) and by Bartlett (1956), the former study giving respiratory rate and volume during extra-coital orgasm and the latter giving respiratory rate, minute volume and tidal volume during coitus. The pattern of respiration during orgasm is not shown graphically in either paper and, therefore, the sudden change in pattern is not discernible.

In respect of respiratory rate and volume in the female, the present findings seem to be in accord with those of Klumbies \& Kleinsorge, but contradict the statement of Bartlett, that there is a "marked rate of fall in the respiratory rate and minute volume following orgasm".

The difference between male and female patterns has not previously been noted. This difference, relating mainly to the female's bouts of apnoea, might possibly be due to a difference in function of sexual climax for the male and female.

The sudden fall in the level of the tracing at the male climax, seen to a much lesser extent in the female's tracing, may be due to a change in position of the chest. In physiological terms, the end-inspiratory posture of the chest becomes gradually more inflated and the tracing rises steeply before the climax. Immediately after the climax the chest is deflated and the level of the tracing falls and remains reasonably constant. Because of this, it is not possible to calculate the oxygen consumption, since the rise in the tracing may not be due solely to oxygen uptake.

\section{Qualitative aspects of orgasmic response}

Many of the individual components of female orgasmic experience described in the present study have previously been mentioned in the literature (Brown, 1967). Levine (1948) and O'Hare (1951) have, as females, subjectively outlined 
the components of orgasm involving contractions. Masters \& Johnson (1966) were able to observe and illustrate these contractions objectively. Payne (1936) has alluded to the subjective 'sucking' quality of vaginal orgasm. Masters \& Johnson (1966) did not find evidence for such a 'suction' mechanism, but their experiments, involving only masturbatory orgasm, seem to be inconclusive (Fox \& Fox, 1967). O'Hare also stresses the qualitative difference between types of orgasm.

Dickinson (1949), describing vaginal orgasm in connection with sperm retention and fertilization, stated that, "The location and retention of the pool of semen may constitute an important factor in conception and sterility.... The deep location of the vaginal fornices and retention of fluid is maximal. ... when the 'vaginal type' of orgasm occurs in its completest form. The latter is accompanied by rhythmic throb of the levator group about once a second during orgasm, together with some contractions after the pinnacle of sensation has passed.... The most effective 'vaginal' orgasm ends in persisting contraction of the levator group, a contraction that holds the lower vagina and introitus closed". Pomeroy (1967) described a female subject who experienced a variable number of orgasms before her partner's ejaculation, but only following his ejaculation could she relax in complete satisfaction. In the same article he described the vocal emissions reminiscent of pain which accompany orgasm.

\section{Temporal aspects}

The 'post-ejaculatory orgasmic reflex' has not been described before as far as we know. Bergler (1947) on the basis of clinical observation wrote "At the same time, perhaps oftener directly following the orgasm of the man, the woman's orgasm takes place, accompanied by involuntary contractions of the genital and pelvic muscles and followed by the feeling of release of sexual tension". The experimental evidence of Boas \& Goldschmidt (1932) indicated that the final orgasm of the female occurs some seconds after ejaculation, though this was not discussed in the text. Bartlett (1956) carried out fourteen experiments, nine measuring heart rate and five giving respiratory measures. Of the first nine experiments, only the second occasion for each of the couples showed a post-ejaculatory female response. Of the second five experiments, a post-ejaculatory orgasm appeared to occur for two subjects who had second trials, though for one of these cases the female orgasm may have been simultaneous with the male one. Since this particular type of orgasm would be most sensitive to conditions of stress, it is not surprising that it does not occur reliably in the laboratory. In our own investigations this response was easily disrupted in the initial experiments. This is because any source of psychological distraction could cause a delay in the female response to the extent that she loses the 'penile plug' and therewith the opportunity to experience orgasm.

Dickinson (1949), however, described the most common form of coitus as one ending in the simultaneous orgasm of the partners, and both Malinowski (1929) and Davenport (1967), describing Melanesian sexual customs, referred to the simultaneous orgasm of the sexual partners. Ellis (1962) described the concept of simultaneous orgasm as a myth, and denied the significance of the temporal aspects of female orgasm. This is obviously a variable and contro- 
versial topic, especially since the concept of simultaneity is not defined precisely anywhere, and could thus conceivably cover a time lag of a few seconds.

The post-ejaculatory orgasm was not mentioned by Masters \& Johnson (1966), and does not appear to have occurred under their observation. The majority of their observations appear to have been made on subjects using self-stimulation or the 'artificial penis', which would not detumesce to form a 'plug' in the vagina, but it would be disconcerting to find that the phenomenon was not present during any of their observations of natural coitus.

One must conclude that, although the events described in the present paper are not unique, they may only apply to a limited population.

\section{ACKNOWLEDGMENTS}

We are greatly indebted to Dr Paul Forgacs, Consultant Chest Physician and Director, South East Regional Respiratory Laboratory, for his constant encouragement, loan of equipment and expert advice. We also wish to thank Dr A. Tanser, King's College Hospital, and Dr Irene Martin, the Institute of Psychiatry, for helpful discussion.

\section{REFERENCES}

Adrian, E. D. (1946) The physical background of perception. Clarendon Press, Oxford.

Bartlett, R. G., JR (1956) Physiological responses during coitus. F. appl. Physiol. 9, 469.

Bergler, E. (1947) Frigidity in the female: misconceptions and facts. Marr. Hyg. 1, 16.

Bergström, S. (1967) Prostaglandins: members of a new hormonal system. Science, N.X. 157, 382.

BoAs, E. P. \& Goldschmidt, E. F. (1932) The heart rate. Thomas, Springfield, Ill.

Brown, D. (1967) Female orgasm and sexual inadequacy. In: An Analysis of Human Sexual Response. Eds. Ruth and Edward Brecher. Deutsch, London.

Campbell, B. \& Peterson, W. E. (1953) Milk 'let-down' and the orgasm in the human female. Human Biol. 25, 165.

Davenport, W. (1967) Sexual patterns in a south west Pacific society. In: An Analysis of Human Sexual Response. Eds. Ruth and Edward Brecher. Deutsch, London.

Dickinson, R. L. (1949) Human sex anatomy, an atlas. Baillière, Tindall \& Cox, London.

ElLIs, A. (1962) Myths about sex compatibility. Sexology, 28, 652.

FARBER, L. H. (1967) "I'm sorry dear". In: An Analysis of Human Sexual Response. Eds. Ruth and Edward Brecher. Deutsch, London.

Fox, C. \& Fox, B. (1967) Uterine suction during orgasm. Br. med. F. i, 300.

FrIBerg, O. (1953) The antidiuretic effect of coitus in human subjects. Acta endocr., Copenh. 12, 193.

Harris, G. W. \& Pickles, V. P. (1953) Reflex stimulation of the neurohypophysis (posterior pituitary gland) and the nature of posterior pituitary hormone(s). Nature, Lond. 172, 1049.

Hoenig, J. \& Hamirton, C. M. (1960) Epilepsy and sexual orgasm. Acta psychiat. neurol. scand. 35, 449.

Klumbies, G. \& Kleinsorge, H. (1950) Circulatory dangers and prophylaxis during orgasm. Int. $\mathcal{F}$. Sex. 4, 61 .

Levine, L. (1948) A criterion for orgasm in the female. Marr. Hyg. 1, 173.

Malinowski, B. (1929) The sexual life of savages in north western Melanesia. Liveright, New York.

Masters, W. H. \& Johnson, V. E. (1961) The physiology of vaginal reproductive function. West. 7 . Surg. Obstet. Gynec. 69, 105.

Masters, W. H. \& Johnson, V. E. (1966) Human sexual response. Churchill, London.

Mendelsohn, M. (1896) Ist das Radfahren also ein gesundheitsgemässe Uebung anzusehen und aus ärztlichen Gesichtspunkt zu empfehlen. Dt. med. Wschr. No. 24, 381.

Mosovich, A. \& Tallafero, A. (1954) Studies on EEG and sex function orgasm. Dis. nerv. Syst. 15, 218.

O'HARE, H. (1951) Vaginal versus clitoral orgasm. Int. J. Sex. 5, 243.

PAYNe, S. (1936) A concept of femininity. Br. F. med. Psychol. 15, 18.

Pomeroy, W. B. (1967) The Masters-Johnson report and the Kinsey tradition. In: An Analysis of Human Sexual Response. Eds. Ruth and Edward Brecher. Deutsch, London.

Scotr, J. C. (1930) Systolic blood pressure fluctuation with sex, anger and fear. 7. comp. Psychol. 10, 97.

Shaptro, M. B. (1966) The single case in clinical psychological research. J. gen. Psychol. 74, 3. 